\title{
A MULTIMEDIA INSTRUCTIONAL PACKAGE ON FOR ENHANCING ACHIEVEMENT IN BASIC SCIENCE
}

\author{
Christian S. Ugwuanyi ${ }^{1 *}$ and Chinedu I.O. Okeke ${ }^{2}$ \\ ${ }^{1}$ Postdoctoral fellow, School of Education Studies, Faculty of Education, \\ University of the Free State, Bloemfontein, 9300, South Africa \\ ${ }^{2}$ Host, Professor and Head, School of Education Studies, Faculty of Education, \\ University of the Free State, Bloemfontein, 9300, South Africa \\ *christian.ugwuanyi@unn.edu.ng
}

\begin{abstract}
This study ascertained the effectiveness of Multimedia instructional package in improving primary school pupils' achievement in basic science at both post and follow-up measures. The design of the study was a randomized control trial experimental design. This design was apt since randomization of subjects was not done and intact classes were used. The sample size was 85 pupils from the two intact classes formed the participant for the study. Basic Science Achievement Test (BSAT) was used to collect data for the study. The internal consistency reliability index of BSAT was determined to be 0.87 using Kuder-Richardson formula 20 while the estimate of the temporal stability of the BSAT was 0.91 using person correlation. Analyses of covariance (ANCOVA) was used in testing the hypotheses at the 5\% probability level. The use of multimedia projection in the form of Computer Assisted Learning (CAL) significantly $(p<.050)$ improved pupils' achievement in basic science. The efficacy of the CAL in improving the pupils' achievement in Basic science was retained at the follow-up measure. Multimedia projection package proved very effective in enhancing the achievement in basic science.
\end{abstract}

Keywords - Achievement, Effectiveness, Basic Science, Multimedia Instructional Package

\section{INTRODUCTION}

The rate of pupils' poor performances in basic science in Nigeria is becoming a disturbance to educators in science education and calls for a paradigm shift in the method of instruction. In line with this, [1] opined that the major cause of the poor performance of students to science subjects is method of teaching in the science classroom in Nigeria. The current teaching strategies commonly used for teaching science have failed to enhance problem-solving skills, curiosity and critical and logical thinking among the science students, there is a great demand to shift to technology integration strategies as a new form of pedagogy [2]. The paradigm shift of integration of Information and Communication Technology (ICT) is paramount since teaching principally involves the passage of information through communication [3]. In light of the above, the researchers sought the effect of multimedia on students' achievement in mathematics and physics.

The twenty-first-century classroom instructional delivery demands the use of ICT. According to [3], ICT is more innovative and could enrich approaches for meaningful

Received: December 23, 2019

Reviewed: February 20, 2020

Accepted: March 2, 2020

* Corresponding Author

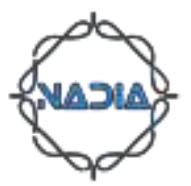


learning. The communication technology comprises of all forms of technology to create, store, exchange information (such as business data, video, audio, still images, text, pictures, etc) with high - speed communication links carrying data, sound and video [3]. The integration of two or more of those aspects of ICT facilities in the communication process is regarded as Multimedia. Multimedia refers to presenting words and pictures that are intended to foster learning [4]. Meaningful learning can occur when learners are presented with words and pictures, as they can start to build mental representations of objects or phenomena [5]. Integrating multimedia, such as static graphics, animations, digital games, interactive simulations, quizzes with immediate feedback, or other widget e-learning activities [6], is essential for effective e-learning [5, 7, 4]. Devices, such as tablets, have the potential to enhance student engagement with learning resources and active and collaborative learning [8]. Multimedia refer to the exciting combination of computer hardware and software that allows integration of text resources, audio, animation, graphics, video to develop an effective presentation on an affordable desktop computer [9]. Buttressing this view, [10] opined that multimedia is characterized by the presence of texts, pictures, sound, animation and video; some or all of which are organized into a coherent program. Thus, multimedia is the presentation of information through multiple channels such as sound, animation, text, audio, image, graphic, video, etc).

The emergence of computers and multimedia technologies has led researchers to develop digital content and systems for teaching various subjects at different levels of education [11]. According to [13], strategically designed and integrated digital games as multimedia have the potential to increase academic and learning effectiveness. Multimedia-supported e-learning is considered useful as it can offer an enjoyable independent learning experience to learners [14].

Studies have examined the effect of multimedia for non-traditional students enrolled in postsecondary education and the implication multimedia can have on achievement and learning outcomes $[13,14,15]$. Through the fun and enjoyment of the self-developed computer-assisted learning, students could engage in an active and effective learning process even when they were not aware of an upcoming test [14]. However, based on the result of [14], the effectiveness of RPG as a supplementary reviewing tool for grade 10 geological instruction fell short of researchers' expectations. This is contrary to other several studies that suggested that students learned effectively with instructional games $[16,17]$.

Besides, [15] found that after exposing students to game-based instruction intervention, the improvement rate of the students in the low-score group was clearly greater than that of the high-score group, thereby indicating that the game-based instruction increased concentration. Studies have been conducted in foreign countries to investigate the effects of multimedia-supported e-learning on students' science learning [18-21]. Austrian seventh-grade pupils' knowledge of groundwater increased significantly after working independently with the multimedia learning software [18]. [21] found that computerbased educational game greatly enhanced students' engagement in science lessons. [22] found that multimedia application in teaching physics had resulted in a significant increase of the quantum and quality of Serbian students' knowledge in all categories, as well as the retention of knowledge quality in the category of applying compared to the traditional method of teaching. [3] found that Multimedia Aided Instructions had a significant effect on students' learning outcomes.

On the basis of the foregoing, the researchers explored the effect of the multimedia projection on the achievement of pupils in basic science. The researchers hypothesized that multimedia projection has a significant effect on the achievement of pupils in basic science. 


\section{METHODS}

\subsection{DESIGN OF THE STUDY}

Pre-test post-test randomized control trial experimental design was adopted by the researchers for the study. Subjects were randomized into experimental and control groups.

\subsection{ETHICAL CONSIDERATIONS}

Faculty of Education, University of Nigeria approved this study through their institutional review board. The researchers strictly followed the ethical standard specifications of the American Psychological Association (APA, 2017).

\subsection{PARTICIPANTS}

A sample of 65 primary 5 pupils formed the participants for the study. Purposive sampling was used in selecting two government-owned primary schools with functional computer laboratory. Pupils were randomized into experimental and control groups using simple random sampling. Besides, the accuracy of the sample size was determined using $G$-Power, version 3.1 which gave 0.84 .

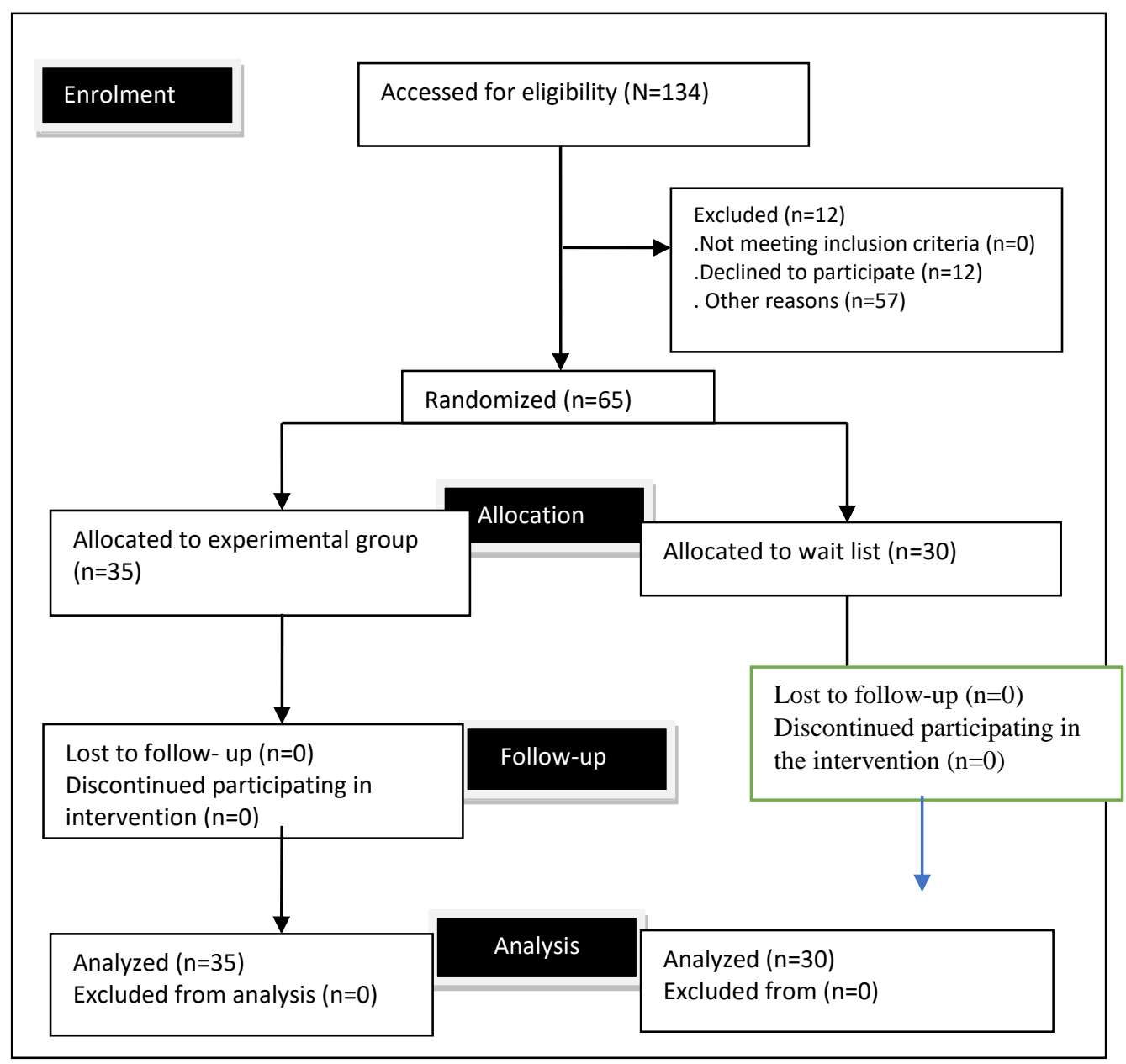

Fig. 1 Flow diagram for Participants Allocation 


\subsection{MEASURE}

The instrument for data collection was the Basic Science Achievement Test (BSAT). BSAT consist of 20-items multiple-choice questions of response options A, B, C \& D. BSAT was developed by the researcher using test-blue print or table of specification to ensure proper content coverage. BSAT was face validated by three test development experts. Content validity of BSAT was determined using a table of specification. An internal consistency reliability index of the instrument was estimated as 0.87 using Kuder-Richardson 20 (KR-20) formula, while the estimate of temporal stability was obtained as 0.91 using Pearson correlation.

\subsection{PROCEDURE}

Prior to the commencement of the treatment, BSAT was administered as a pretest to the two groups to collect baseline data for the study. After that, the treatment commenced after that pretest. The experimental group was exposed to multimedia projection in the form of computer-assisted learning (CAL) while the control group was exposed to the normal talk and chalk method of teaching. The contents of the instruction were drawn from primary five Basic science core curriculum of the Federal Ministry of Education. The experiment was conducted during the normal school periods following the school timetable. At the end of the experiment, which lasted for six weeks, the researchers administered the posttest to the participants in the two groups. After one month of the administration of the posttest, follow-up measure was administered.

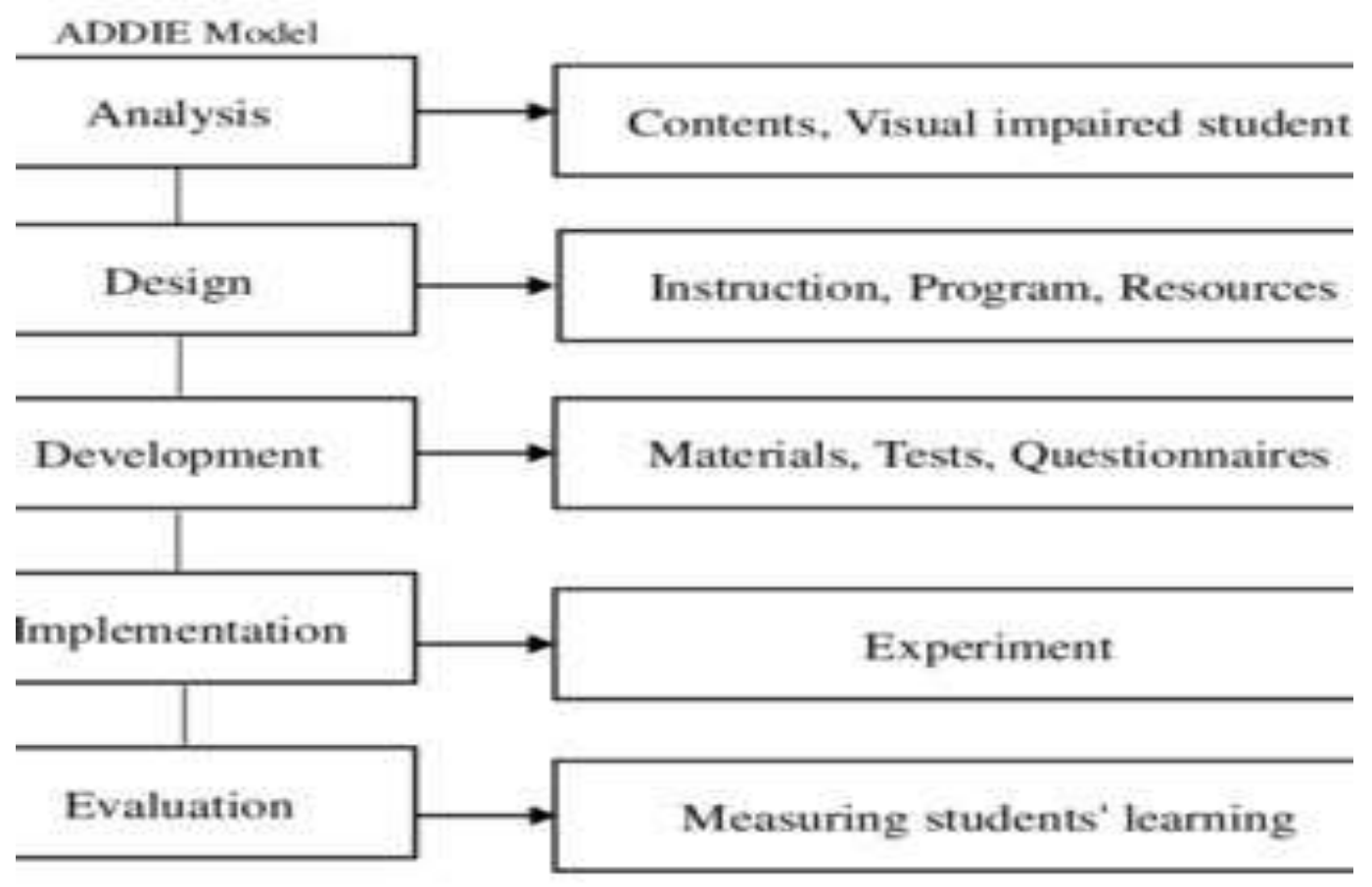

Fig. 2 Development of Computer Assisted Learning 


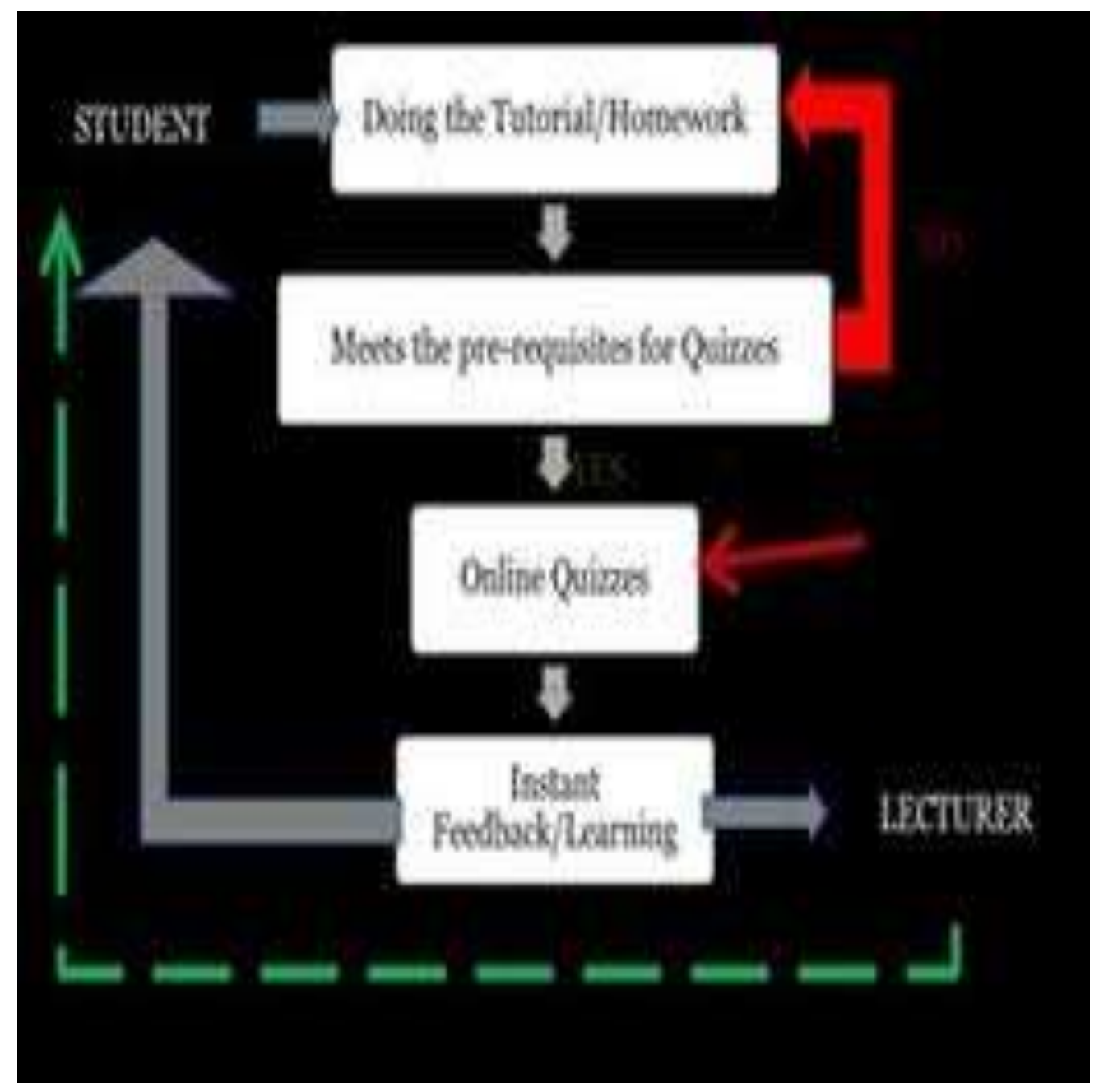

Fig. 3 Computer Assisted Learning through online platform

\subsection{DATA ANALYSIS}

The effectiveness of multimedia projection in enhancing the achievement of pupils in Basic science was determined using analysis of covariance (ANCOVA). The effect size of the treatment was reported using Partial Eta squared. The assumption of the sphericity of the test statistic was tested using the Mauchly test of sphericity which was not significant (Mauchly $W=0.854, p=.713$ ), implying that the assumption was not violated. Thus, the variances of the differences between all combinations of the related measures are equal. The analysis was done using statistical package for social sciences version 18.0. 


\section{DESIGN}

PRE-TEST, POST-TEST RANDOMIZED CONTROL TRIAL EXPERIMENTAL

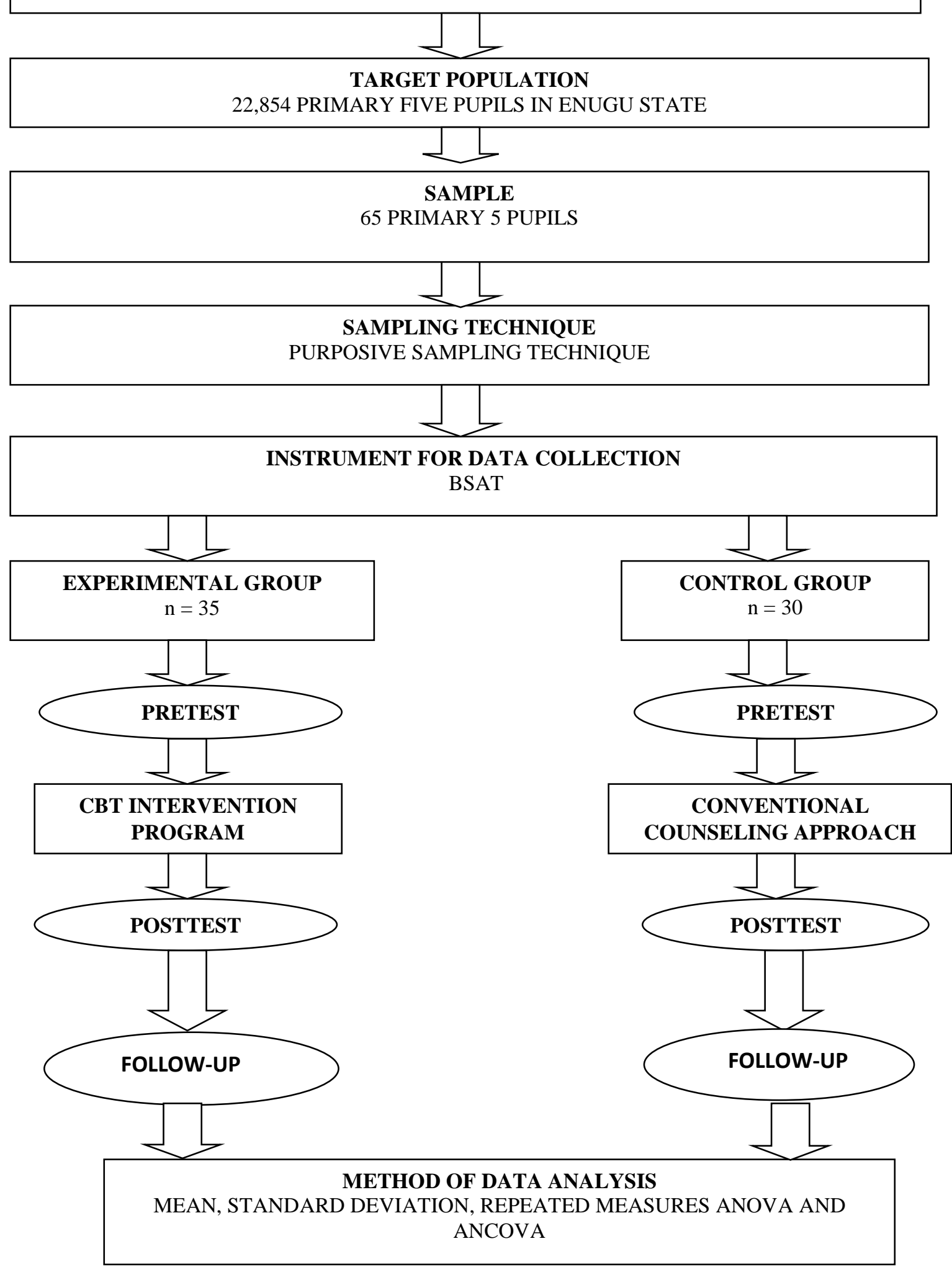

Fig. 4 Schematic Representation of the Methodology 


\section{RESULTS}

Table I. Demographic information of the participants

\begin{tabular}{lllll}
\hline Variables & Categories & $\begin{array}{l}\text { Treatment } \\
\text { group }\end{array}$ & Control Group & Total \\
\hline Gender & Male & $14(40.00 \%)$ & $11(36.67 \%)$ & $25(38.46 \%)$ \\
& Female & $21(60.00 \%)$ & $19(63.33 \%)$ & $40(61.54 \%)$ \\
& Total & $35(100 \%)$ & $30(100 \%)$ & $65(100 \%)$ \\
Location & Urban & $22(62.86 \%)$ & $18(60.00 \%)$ & $40(61.54)$ \\
& Rural & $13(37.14 \%)$ & $12(40.00 \%)$ & $25(38.46)$ \\
& Total & $35(100 \%)$ & $30(100 \%)$ & $65(100 \%)$ \\
& & & & \\
Mean Age & M SD & $10.02 \pm 1.43$ & $10.14 \pm 1.55$ & \\
\hline
\end{tabular}

Table I shows that out of the 65 participants, 25 (38.46\%) are male pupils and 40 (61.54\%) are female pupils. 40 pupils representing $61.54 \%$ are pupils in urban primary schools while 25 pupils representing $38.46 \%$ of the participants are pupils in rural primary school. Mean age of pupils in the experimental group is $10.02 \pm 1.43$ while that of the pupils in the control group is $10.14 \pm 1.55$.

Table II. Analysis of covariance of the effect of a multimedia instructional package on pupils' achievement in Basic Science

\begin{tabular}{llllllll}
\hline Time & Group & Mean (SD) & $\mathrm{F}$ & $\mathrm{p}$ & $\mathrm{n}^{2}$ & $\Delta \mathrm{R}^{2}$ & 95\%CI \\
\hline \multirow{3}{*}{ 1 Pre-test } & Experimental & $17.65(6.34)$ & & & & & \\
& Control & $18.40(5.78)$ & .247 & .621 & .004 & -.010 & $-3.76,2.28$ \\
2 Post-test & Experimental & $30.43(4.27)$ & & & & & \\
& Control & $20.16(4.98)$ & 80.375 & $<.050$ & .565 & .791 & $8.04,12.61$ \\
3 Follow-up & Experimental & $30.71(4.05)$ & 89.874 & $<.050$ & .592 & & \\
& Control & $19.67(5.33)$ & & & & .801 & $8.72,13.37$ \\
\hline
\end{tabular}

Mean $(S D)=$ Mean (Standard Deviation), $p=$ probability value, $C I-$ Confidence Interval, $\eta^{2}$ - effect size, $\Delta R^{2}=$ Adjusted $R^{2}$

Table II reveals that there was no significant difference in the achievement scores of pupils in the experimental and control groups as measured by BSAT, $F(1,62)=.247, p$ $=.621, \mathrm{n}^{2}=.004, \Delta \mathrm{R}^{2}=-.010$. At the post test and follow-up measures, the effect of multimedia instructional package on pupils' achievement in basic science was significant, $F(1,62)=80.375, p<.050, \mathrm{y}^{2}=.565, \Delta \mathrm{R}^{2}=.519 ;$ and $F(1,62)=89.874, p<.050, \mathrm{y}^{2}$ $=.592, \Delta \mathrm{R}^{2}=.582$.

Table III. Tests of Within-Subjects Effects for the Experimental Group

Measure: BSAT

\begin{tabular}{llcrcrrr}
\hline Source & \multicolumn{2}{c}{ Type III Sum of } & & & & \multicolumn{2}{c}{ Partial Eta } \\
Time & Sphericity Assumed & .937 & df & Mean Square & F & Sig. & Squared \\
& Greenhouse-Geisser & .937 & 1 & .937 & 1.333 & .257 & .039 \\
& Huynh-Feldt & .937 & 1.000 & .937 & 1.333 & .257 & .039 \\
& Lower-bound & .937 & 1.000 & .937 & 1.333 & .257 & .039 \\
\hline
\end{tabular}


Table III revealed that the mean achievement scores of the experimental group were not significantly different at post and follow-up measures, $F(1,34)=1.333, p>0.05, \mathrm{y}^{2}$ $=.039$.

The results also showed that there was no significant interaction effect of time and treatment on the achievement of pupils in basic science, $F(2,58)=.467, p=.629, \mathrm{y}^{2}$ $=.016$. Figure 2 shows the graph of the interaction effect of time and treatment.

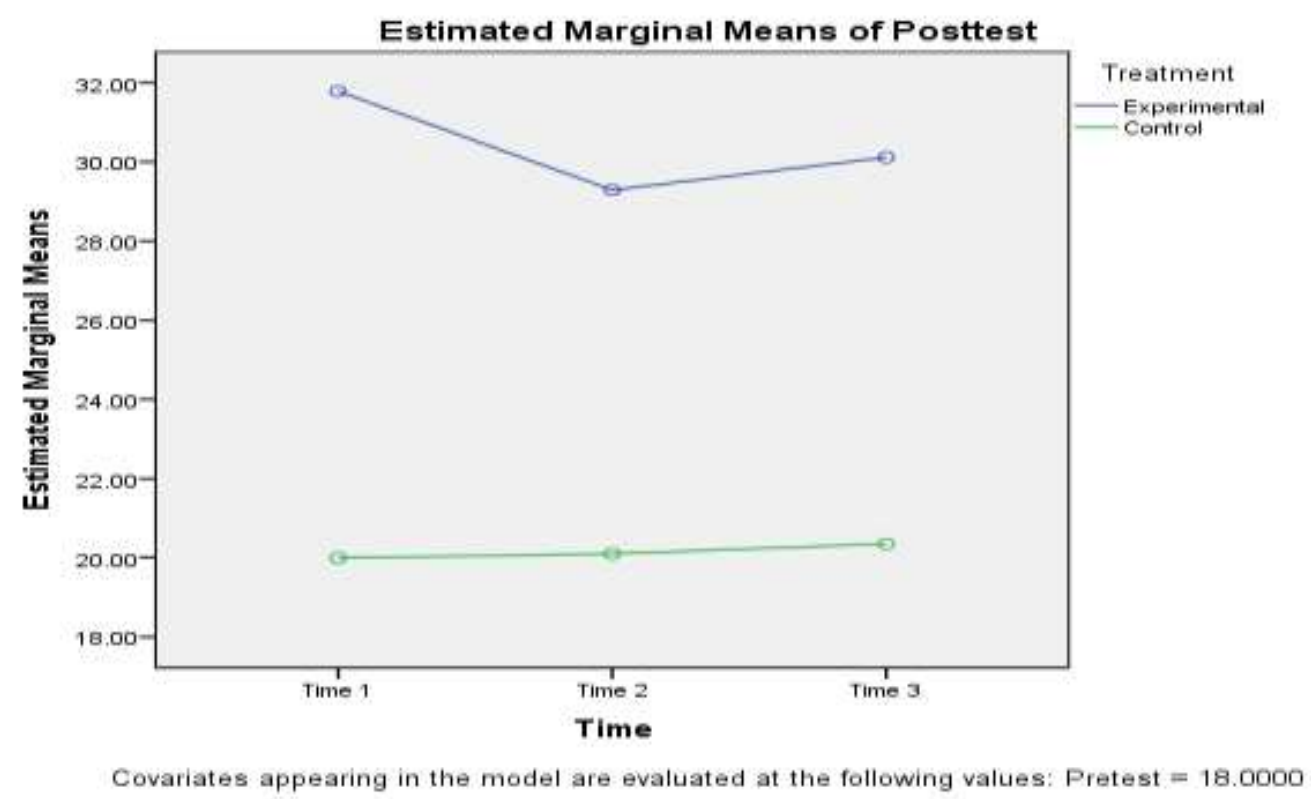

Fig. 5 Graph of the interaction effect of time and treatment.

\section{DISCUSSION OF THE FINDINGS}

The results of the analysis revealed that the multimedia instructional package significantly improved the achievement of pupils in basic science. It was further found that there was no significant change in the scores of the experimental group participants at posttest and follow-up measures. This implies that the participants were able to retain their improved achievement at the follow-up assessment. These findings go to show the effectiveness of the multimedia instructional package in improving the achievement of pupils in Basic science. The outcome of this research came out this way because the exposure of the pupils to multimedia instructional package activated the interest of the pupils leading to their active participation in the classroom interaction. The pupils at the course of the treatment were highly involved in the classroom interactions for the 3 weeks the treatment lasted leading to their improved achievement compared to their counterparts in the control group. Similar studies have been conducted to investigate the effects of multimedia-supported e-learning on students' science learning [18-21]. Austrian seventhgrade pupils' knowledge of groundwater increased significantly after working independently with the multimedia learning software [18]. [21] found that computerbased educational game greatly enhanced students' engagement in science lessons. Students under Multimedia Aided Instructions had a better outcome than their colleagues in traditional teaching method [3]. Multimedia application in teaching physics had resulted in a significant increase of the quantum and quality of students' knowledge in all categories, as well as the retention of knowledge quality in the category of applying compared to the traditional method of teaching [22].

In a similar study, [11] found that digital game-based learning significantly improved the achievement of primary school pupils at both the post-test and follow-up measures. It was found that the pupils who were exposed to DGBL, participated actively during the 
teaching-learning situation than those who were exposed to the traditional method of teaching. [23] found that the integration of digital games in the educational environment has shown positive results in enhancing the learning process [23]. According to [23], the educational game improves learning processes, and at the same time, renew teaching competences of mentors integrating information and communications technology (ICT), storytelling, and digital game-based learning (DGBL) with ease of realising new didactic product.

These findings aligned with the findings of [15]. After exposing students to gamebased instruction intervention, the improvement rate of the students in the low-score group was clearly greater than that of the high-score group, thereby indicating that the game-based instruction increased concentration [15]. According to [25], computer games directly support learning by giving pupils an opportunity to develop knowledge and cognitive skills in an emotional way, to make decisions in critical situations by solving problems, to learn by researching and to experience situational learning.

\subsection{STRENGTH OF THE RESEARCH}

There is a dearth of literature on the effectiveness of multimedia instructional package on primary school pupils' achievement in basic science. Thus, the outcomes of this research have contributed to the scholarly discussions on the effectiveness of multimedia instructional package on primary school pupils' achievement in basic science.

\subsection{LIMITATIONS}

The cultural diversity of the participants raises the question about whether cultural background may influence the effectiveness of multimedia instructional package on primary school pupils' achievement in basic science. Thus, the generalizability of the findings of this research is limited to situations with similar participants.

\subsection{DIRECTION FOR FURTHER RESEARCH}

Replicating the study in multi-cultural settings would offer an opportunity to confirm the findings of this research.

\section{CONCLUSION}

The effect of a multimedia instructional package on primary school pupils' achievement in basic science has been empirically found to be significant. This may be due to the fact that during the treatment periods, the pupils who were in the experimental group were very active in the learning process than their counterparts. Hence, the application of multimedia instructional package enhances pupils' achievement in basic science.

\subsection{RECOMMENDATIONS}

In light of the findings of this research, the researchers made the following recommendation;

1. Primary school teachers should be trained on how to use the multimedia instructional package to deliver basic science contents to the pupils.

2. State government should make adequate provision of ICT learning facilities for proper implementation of a multimedia instructional package for classroom instructional delivery. 


\section{REFERENCES}

[1] Ukoh, E. E \& Adewale, J. G. Science teachers' attitude to ICT integration in science education in Oyo State, Nigeria. West African Journal of Education, XXXIV (2014).

[2] Shah, I and Khan, M. Impact of multimedia-aided teaching on students' academic achievement and attitude at elementary level. US-China Education Review. 5(5) (2015).

[3] Kareem, A.A. The use of multimedia in teaching biology and its impact on students' learning outcomes. The Eurasia Proceedings of Educational \& Social Sciences (EPESS), 9(2018), 157-165.

[4] Mayer, R. E. Using multimedia for e-learning. Journal of Computer Assisted Learning, 33(5) (2017), 403-423.

[5] Clark, R. C., \& Mayer, R. E. E-learning and the science of instruction: Proven guidelines for consumers and designers of multimedia learning. John Wiley \& Sons (2016).

[6] Fouh, E., Breakiron, D. A., Hamouda, S., Farghally, M. F., \& Shaffer, C. A. Exploring students learning behavior with an interactive e-textbook in computer science courses. Computers in Human Behavior, 41(2014), 478-485.

[7] Khamparia, A., \& Pandey, B. Impact of interactive multimedia in E-learning technologies, (2017). pp 171-199.

[8] Stec, M., Smith, C., \& Jacox, E. Technology enhanced teaching and learning: Exploration of faculty adaptation to iPad delivered curriculum. Technology, Knowledge and Learning (2019)., 1-15.

[9] Malik, S \& Agarwal, A. Use of media as a new educational tool - A study. International Journal of Information and Education Technology, 2 (5) (2012).

[10] Neo, M. Learning with multimedia: Engaging students in constructivist learning. International Journal of Instructional Media, 34(2) (2007).

[11] Ugwuanyi, C.S., Okenyi, E.C., Ezema, V., \& Amoke, C. Effect of digital game-based learning on achievement of primary school pupils in sciences in Enugu State, Nigeria. Journal of Educational Research on Children, Parents \& teachers, 1(1) (2020), 35-44.

[12] Winnie, W. M.S; Yu, C \& Zhi, H.W. Multimedia e-learning and self-regulated science learning: A study of primary school learners' experiences and perceptions. Journal of Science Education and Technology 28(2018):508-522. https://doi.org/10.1007/s10956-019-09782-y.

[13] Turner, P.E., Johnston, E., Kebritchi, M., Evans, S \& Heflich, D.A. Influence of online computer games on the academic achievement of non-traditional undergraduate students. Cogent Education, 5(2018), 1437671

[14] Chia-Li, D.C., Ting-Kuang, Y \& Chun-Yen, C. The effects of game-based learning and anticipation of a test on the learning outcomes of 10th grade geology students. Eurasia Journal of Mathematics, Science \& Technology Education, 12(5) (2016), 1379-1388 doi: 10.12973/eurasia.2016.1519a

[15] Ming-Hsiu, M. C., Shih-Ting, T.M \& Chi-Cheng, C. Effects of game-based instruction on the results of primary school children taking a natural science course. Educational Sciences, 9, 79(2019); doi:10.3390/educsci9020079.

[16] Chen, C.H., Wang, K.C., \& Lin, Y.H. The comparison of solitary and collaborative modes of gamebased learning on students' science learning and motivation. Educational Technology and Society, 18(2) (2015), 237-248.

[17] Hwang, G.J., Wu, P.H \& Chen, C.C. An online game approach for improving students' learning performance in web-based problem-solving activities. Computers and Education. 59(1) (2015), 12461256.

[18] Unterbruner, U., Hilberg, S., \& Schiffl, I. Understanding groundwater-students' pre-conceptions and conceptual change by means of a theory-guided multimedia learning program. Hydrology and Earth System Sciences, 20(6) (2016), 2251-2266.

[19] Sun, J., Flores, J., \& Tanguma, J. E-textbooks and students' learning experiences. Decision Sciences Journal of Innovative Education, 10(1) (2012), 63-77.

[20] Li, M. C., \& Tsai, C. C. Game-based learning in science education: A review of relevant research. Journal of Science Education and Technology, 22(6) (2013), 877-898.

[21] Khan, A., Ahmad, F. H., \& Malik, M. M. Use of digital game-based learning and gamification in secondary school science: The effect on student engagement, learning and gender difference. Education and Information Technologies, 22(6) (2017), 2767-2804.

[22] Danijela, R.C; Zagorka, L.C; Dušanka, O \& Mirjana, S. The application of multimedia and its effects on teaching physics in secondary school. Година 46 - Број 2 - Децембар (2014), 339-363. DOI: 10.2298/ZIPI1402339R. https://www.researchgate.net/publication/276237081 doi: $10.17265 / 2161-623 X / 2017.09 .003$

[23] Trybus, J. Game-based learning: What it is, why it works, and where it's going (2014). Retrieved from www. simcoachgames.com/pdfs/WP-Trybus-Game-basedlearning.pdf

[24] Maraffi, S; Sacerdoti, F.M \& Paris, E. Learning on Gaming: A New Digital Game Based Learning Approach to Improve Education Outcomes. US-China Education Review A, September, 7(9) (2017), 421-432

[25] Holzinger, A., Nischelwitzer, A., Meisenberger, M. Lifelong - Learning support by m-learnig: Example scenarios, eLearn Magazine (2005). https://doi.org/10.1080/2331186X.2018.1437671 